Revista de Filología Alemana

ISSN: 1133-0406

\title{
Raffinierte Spracharabesken und rhythmische Wortkaskaden: zu Reto Hännys Prosawerken vor dem Hintergrund sprachästhetischer Tendenzen in der Deutschschweizer Literatur
}

Dorota Sośnicka ${ }^{1}$

Recibido: 9 de enero de 2019 / Aceptado: 1 de febrero de 2019

Zusammenfassung. Der Aufsatz charakterisiert die wichtigsten Merkmale und Voraussetzungen der sprachästhetischen Tendenzen, wie sie sich seit Mitte der 1970er Jahre in der Deutschschweizer Gegenwartsliteratur bemerkbar machten, und überblickt das Schaffen einiger ,Sprachartisten', die einerseits in Reaktion auf die Undurchschaubarkeit der Realität, andererseits als Ausdruck der zunehmenden Sprachreflexion und Sprachskepsis ihre hochartifiziellen Werke vorgelegt haben. Vor diesem Hintergrund konzentriert sich der Beitrag auf das Schaffen Reto Hännys als eines der radikalsten Sprachexperimentatoren, dessen von Intertextualität geprägte, bildstarke und rhythmisierte Texte im Hinblick auf ihre Problematik und Komposition besprochen werden.

Schlüsselwörter: Sprachästhetik; Sprachartistik; Sprachskepsis; Literaturexperimente.

[en] Ingenious Linguistc Arabesques and Rhythmic Word Cascades: the Prose Works of Reto Hänny in Relation to Aesthetic Linguistic Trends in German-Swiss Literature

\begin{abstract}
This article characterises the most important features and assumptions of the trend towards aesthetic use of language which has been present in contemporary German-Swiss literature since the middle of the 1970s; it surveys the work of several 'language artists' whose highly contrived publications are a reaction on the one hand to the opacity of reality and on the other to an increasing scrutiny and distrust of language. Against this background, the article concentrates on the work of Reto Hänny as the most radical of the experimenters; his works, which are marked by extensive intertextuality, powerful imagery and rhythmic structures, are discussed in relation both to the problems they address and to the manner of their composition.
\end{abstract}

Keywords: Language Aesthetics; Language Artistry; Language Scepticism; Literary Experiments.

[es] Ingeniosos arabescos lingüísticos y cascadas rítmicas de palabras: la prosa de Reto Hänny en relación con las tendencias estéticas lingüísticas en la literature alemano-suiza

Resumen. El artículo pretende definir los rasgos y las premisas más importantes de las tendencias estéticas presentes en la literatura de la Suiza alemana desde mediados de los años 70, al tiempo que analiza la obra de algunos "artistas de la lengua" cuyas obras extremadamente artificiales han surgido,

1 Uniwersytet Szczeciński, Wydział Filologiczny (Polska)

E-Mail: dorota.sosnicka@usz.edu.pl. 
por un lado, como reacción a la opacidad de la realidad, por otro, como expresión de una reflexión y a un escepticismo lingüísticos cada vez mayores. Sobre este trasfondo el artículo se centra en la obra de Reto Hänny, uno de los autores que más han experimentado con el lenguaje; sus trabajos, caracterizados por una gran dosis intertextualidad, una fuerte imaginería y estructuras rítmicas se analizan en relación con su problemática y su proceso de composición.

Palabras clave: Estética del lenguaje; arte del lenguaje; escepticismo lingüístico; experimentación literaria.

Inhaltsverzeichnis. 1. Die Sprachästhetik in der Deutschschweizer Gegenwartsliteratur. 2. Die Sprachskepsis in den Werken Hermann Burgers und Jürg Leaderachs. 3. Satzarchitektur und Wortmusik: $\mathrm{Zu}$ Reto Hännys Prosawerken.

Cómo citar: Sośnicka, D., «Raffinierte Spracharabesken und rhythmische Wortkaskaden: Zu Reto Hännys Prosawerken vor dem Hintergrund der sprachästhetischen Tendenz in der Deutschschweizer Literatur», Revista de Filología Alemana 27 (2019), 97-116

\section{Die Sprachästhetik in der Deutschschweizer Gegenwartsliteratur}

Bereits seit der Moderne wurden in der Literatur immer wieder ästhetische Fragen diskutiert und sprachliche und formelle Experimente ungebrochen fortgeführt, doch geschah dies meistens abseits von den literarischen Hauptströmungen und schien zugleich die Deutschschweizer Literatur kaum zu betreffen. Wichtige Impulse zu diversen Sprachexperimenten kamen insbesondere von der in der Zeit des ersten Weltkriegs in Zürich entstandenen Dada-Bewegung, an der allerdings außer Friedrich Glauser kein Schweizer Autor mitbeteiligt war. Großer Beliebtheit erfreute sich auch in den 1950er und 1960er Jahren die Konkrete Poesie, in der die Sprache keine abbildende, sondern vielmehr eine bildende Funktion hat, doch ihr Begründer, der Schweizer Schriftsteller Eugen Gomringer (geb. 1925), wirkte vor allem in Deutschland und kaum in der Schweiz, deren Literatur sich indes in einem traditionell geprägten Vorgehen auf das typisch Helvetische, auf eine idyllische Betrachtung der Provinz, zu konzentrieren schien, außerdem kennzeichnete sie der Hang zur Didaktisierung und Moralisierung des Geschilderten. Dies trug zur Entstehung verschiedener Vorurteile dieser Literatur gegenüber, die lange Zeit als langweilig und ,harmlos ${ }^{6}$ abgetan wurde (vgl. Sośnicka 2008: 9-10). Doch nachdem in der Nachkriegszeit die Deutschschweizer Literatur eigentlich nur durch die Werke von Max Frisch und Friedrich Dürrenmatt, die auch außerhalb der schweizerischen Grenzen große Beachtung fanden, verschiedene Erneuerungen erfuhr, änderte sich die literarische Situation grundsätzlich mit dem Hervortreten der nächsten Generation von Schweizer Schriftstellern, als 1959 der Roman Der Stumme von Otto F. Walter erschien. So entstand in den 1960er Jahren eine Vielzahl von politisch und gesellschaftlich engagierten Büchern, die gleichzeitig eine zunehmende Sprachsensibilisierung offenbarten, was mit einer immer mehr um sich greifenden Sprachskepsis und der daraus resultierenden Sprachreduktion einherging. Zum besonders prägnanten Kennzeichen dieser neuen Tendenz wurde der sogenannte „Wandtafelsatz“ (Burger 1984: 37) Peter Bichsels, wie er ihn in seinen berühmten Kurzgeschichten Eigentlich möchte Frau Blum den Milchmann kennenlernen (1964) vorgeprägt hat (vgl. Sośnicka 2008: 67-75). In Reaktion auf diese allgemeine Sprachreduktion und -verknappung der engagierten Literatur der 1960er Jahre machte sich aber um die Mitte der 1970er 
Jahre ein relativ breit angelegtes Streben nach einer artistischen Verfremdung des Vertrauten bemerkbar, eine Hinwendung zur Sprachästhetik und zur virtuosen Sprachopulenz mit der Neigung zu einem grotesken bis aggressiven Sprachwitz. Einerseits wollte man durch die betonte Sprachartistik die immer schmerzhafter erfahrene Undurchschaubarkeit der Realität zum Ausdruck bringen, andererseits entsprang diese sprachästhetische Tendenz der zunehmenden Sprachreflexion und dem Bedürfnis, über eine eigene und persönliche Sprache zur Ich-Identität zu finden. Die neue Wertschätzung der eigenen Sprache mehrerer Deutschschweizer Autorinnen und Autoren zeigte sich u. a. im Einfließen zahlreicher, früher stets aufmerksam korrigierter Helvetismen in die literarischen Texte sowie in einer eigenständigen Grammatik. Die Auflehnung gegen grammatische Vorgaben, verbunden mit dem Protest gegen erstarrte gesellschaftliche Normen, aber auch die neu erwachte Fabulierlust zeitigten somit - Hermann Burger zufolge - eine ,stilistische[...] Entwicklung der Schweizer Literatur vom didaktischen Wandtafelsatz zur polypenhaften Perioden-Konstruktion“ (Burger 1984: 37), was sich hauptsächlich in den „Schnecken-, Schachtel- und Labyrinthsätzen" (ebd.: 38) der sogenannten Sprachartisten (vgl. Sośnicka 2008: 76-117) offenbarte.

Die neue Tendenz zum fabulierlustigen, opulenten Erzählen begann bereits 1970 Gestalt zu gewinnen, als Gerold Späth (geb. 1939) nach einer langen Suche nach einem Herausgeber seinen Erstlingsroman Unschlecht veröffentlichte, mit dem er allerdings noch vereinzelt dastand. Inmitten der in den 1960er Jahren auf die Tagespolitik eingestellten, engagierten Literatur wirkte nämlich sein Werk, in dem er ,alle Register der Sprache“ zog und „fluchmeierte, [drauflos] nassauerte [...], dass es eine Freude war" (Burger 1984: 37), geradezu wie ein ,Fremdkörper'. Doch schon bald folgten Späths Unschlecht auch die Erzählwerke von E. Y. Meyer (geb. 1946) Ein Reisender in Sachen Umsturz (1972) und In Trubschachen (1973) mit ihren weitausgebauten, sich ins Unendliche ziehenden Schachtelsätzen, die die Literaturkritik zwar „,sofort durch unverkennbare Zeichen von Könnerschaft beeindruckt, allerdings auch durch den ,verhäkelten' Text und die ,Orgien im Plusquamperfekt ‘ irritiert" (Krättli 1994: 2) haben. Nach dem Erscheinen der sprachmächtigen „Pilotbücher“ (Burger 1984: 37) von Späth und Meyer breitete sich in der Deutschschweizer Prosa immer mehr ein poetisches Erzählen aus, und zwar sowohl bei den schon anerkannten Autoren, wie u. a.: Otto F. Walter (1928-1994), Hans Boesch (1926-2003), Erika Burkart (1922-2010), Christoph Mangold (1939-2014), Paul Nizon (geb. 1929) oder Adolf Muschg (geb. 1934), als auch in den Debüts der nächsten Schriftstellergeneration. In diesem Zusammenhang wären vor allem die Werke von Erica Pedretti (geb. 1930) und Gertrud Leutenegger (geb. 1948) zu erwähnen, die als hervorragende Beispiele für ,weibliches Schreiben“ in der Deutschschweizer Gegenwartsliteratur gelten. Während sich also Erica Pedretti ihren ganz besonderen, suchenden und beweglichen, zugleich zögernden und stockenden Sprachrhythmus erarbeitet hat, bei dem der Bewusstseinsstrom ihrer Protagonistinnen immer wieder durch wirkliche und imaginierte Dialoge durchbrochen wird und mit dem sie ihre Weltsicht, ihr Hängen am Vergangenen mehr noch als am Gegenwärtigen, zu verteidigen suchte, erschuf Gertrud Leutenegger eine höchst poetische und bildstarke Sprache, die Entgegengesetztes bruchlos miteinander verknüpft und neue Wortschöpfungen kreiert, sich freiem Assoziieren öffnet und bisweilen der grammatischen Korrektheit zuwiderläuft, was dem Konzept der Autorin entspricht, sich von semantischen und sozialen Zwängen zu emanzipieren. 
Als ein hervorragender Sprachartist der Deutschschweizer Literatur gilt auch der stille Poet des Gewöhnlichen und ,der weltläufige Provinzler` Gerhard Meier (19172008), der nach dem Tod von Max Frisch (1911-1991) und Friedrich Dürrenmatt (1921-1990) den Ruf genossen hat, ein „Doyen der zeitgenössischen Schweizer Literatur" (Morlang 2008: 23) zu sein. Der besondere Rang, den Meier dem poetischen Sprechen beigemessen hat, entstammte seinem inneren Bedürfnis, mit der Sprache die ihn umgebende Welt in eine ästhetische zu verwandeln und sie im Klang der Wörter zu erfassen (vgl. Sośnicka 1999). Eine wesentliche Rolle spielt in Meiers Prosa zugleich die Musikalität der Sprache, was vornehmlich durch eine ,musikalische' Wortwahl und eine ,arabeske' Syntax erzielt wird. Diese ,arabeske' Syntax, die - verschiedenen Assoziationen folgend - die Gedankenabläufe im menschlichen Gehirn nachahmt, führt in dichterischer Praxis zur Bildung einer Vielzahl von Nebensätzen und Nebennebensätzen, sodass zum Verständnis solcher weitausgebauten Sätze zahlreiche Wiederholungen und Präzisierungen nötig sind, die wiederum neue Nebensätze ergeben. Bei diesem Erzählprinzip, das für Meiers Romane so signifikant ist, beruft sich der verhinderte Architekt sowohl auf den die Arabesken liebenden Jugendstil als auch auf Robert Walser:

Denn einer der großen, vielleicht der größte Spracharabeskler - Robert Walser sei ja nun tatsächlich (oder historisch eben) im Jugendstil anzusiedeln. Erübrigen sollte sich hinzuweisen, dass es sich dabei nicht nur um die syntaktischen, sozusagen vordergründigen arabeskalen Sprachfiguren handeln könne, sondern vielmehr um jene diesen syntaktischen Figuren zugrundeliegenden arabeskalen Gedankenbewegungen oder Gedankenabläufe gewissermaßen, welche ihrerseits vielleicht wiederum im Zusammenhang stünden mit der rankenhaften oder ornamentalen Struktur des Gehirns gleichsam. Was einerseits für Robert Walser und den Jugendstil - andererseits gegen eine simplifizierte Syntax und gegen den Spruch „Alles Große ist einfach“s sprechen würde (Meier 1987: 36).

Zur Herausbildung musikalischer Effekte trägt in Meiers Büchern auch eine an Walsers Erzählstil erinnernde, sich am Spaziergang orientierende und beinahe zufällige Verknüpfung der behandelten Themen und Motive, Impressionen und Reflexionen, was zusammen mit einer ironischen, relativierenden Distanznahme zu den eigenen Aussagen dem Erzählten jegliche Spannung nimmt und die Äußerungen gleichsam von der Wirklichkeit abhebt. Auf diese Weise geraten die poetischen Visionen der Realität in einen unfixierten, also schwebenden und fließenden Zustand, der ,melodisch' erklingt. Diese poetische, von Musik erfüllte Weltkreation ist aber ständig auch vom Sprachzweifel unterlaufen und sie reflektiert in verschiedenen Wortspielen einen unkritischen Sprachgebrauch, erzielt absichtlich unterschiedliche Klangstörungen und Verfremdungseffekte, die den Leser verstören und ihn somit aus seinen festgefahrenen Sprach- und Denkmustern herausreißen wollen. Denn diese Sprache richtet sich gegen allerlei Vereinfachungen, gegen den phrasenhaften Gebrauch der Wörter, und somit gegen allerlei falsche Vorstellungen und Erwartungen, gegen Erlebnis- und Erfahrungsklischees.

Dieses in den Werken des subtilen Ironikers Gerhard Meier vernehmbare kritische Verhältnis zur Sprache ist allerdings für die meisten sogenannten Sprachartisten charakteristisch. Denn man schafft zwar riesige Wortkaskaden und lange, sich verästelnde Sätze, doch dem Kunstmittel ,Sprache“ begegnet man mit größter Vorsicht, 
mit Misstrauen und Wachsamkeit, und man versucht zugleich, den Leser für die Möglichkeiten und Grenzen der Sprache zu sensibilisieren. Während man also einerseits die literarische Sprache entgegen der rationalen und pragmatischen Alltagssprache poetisiert, sorgt man andererseits für verschiedene Verfremdungseffekte und deckt auf diese Weise die Sinndefizite der Sprache auf.

Die sprachkritische Tendenz offenbarte sich insbesondere in den sprachwuchtigen Prosawerken Hermann Burgers (1942-1989), Jürg Laederachs (1945-2018) und Reto Hännys (geb. 1947), in denen es weniger darum geht, die Welt zu poetisieren und einen Zusammenhang zu vermitteln, als vielmehr darum, die Sprache selbst zum alleinigen Sinn und zur Stimmungsträgerin zu machen. Diese Autoren problematisieren nämlich in ihren Texten einen unreflektierten Umgang mit der Sprache und versuchen mit einem experimentellen Gestus, ein Gegengewicht zu der Glätte und Rationalität der konventionalisierten Sprache zu schaffen. Daher forderte Reto Hänny 1981, „dass man die Sprache der Schulgrammatik, die Dudengrammatik, die herrschende Grammatik von unten her versucht aufzusprengen, aufzusplittern, sei's um zu zeigen, dass das ein Gebäude ist, das gar nicht so intakt ist wie die Gedanken, die dabei in einer Geradlinigkeit ausgedrückt werden“" (Hänny 1981: 54). Allerdings paart sich in den Werken dieser drei Sprachartisten die Freude am Sprachexperiment und an einer ,wuchernde[n] Intertextualität“ häufig mit einem breiten „Spektrum von politischer Parteinahme“" (Haupt 1998: 108). Daher sind ihre ersten Texte als ,Berichte“ über den schlechten Weltzustand konzipiert: den Untertitel „Bericht“ trägt ebenso Burgers Erstling Schilten (1976) wie auch Hännys Ruch (1979). Demzufolge erscheinen beide Romane als ,,beredte Schadensprotokolle, welche die Zustände und Verfasstheiten einer den einzelnen zerstörenden Gesellschaft und einer katastrophisch gewordenen Welt rapportieren sollen“ (Aeschbacher 1998: 142). Den modernen Zerstörungstendenzen unterliegt in beiden Büchern auch die Sprache selbst, die an die Dinge nicht mehr heranreicht und somit bei der Wiedergabe des Weltzustands versagen muss.

\section{Die Sprachskepsis in den Werken Hermann Burgers und Jürg Laederachs}

Die sprachlichen Defizite thematisierte in seinen Büchern ausdrücklich der Schriftsteller und Germanist, Hermann Burger, der auch als Literatur-Vermittler tätig war und über die neuen Entwicklungen in der Deutschschweizer Literatur informierte. Dieser ,gelehrte Dichter ${ }^{6}$, den - wie er dies selber beklagte - sein beträchtliches literaturtheoretisches und -historisches Wissen eigentlich ,zu resignierendem Verstummen" (Zumsteg 2011: 243) zwingen musste, verstand es jedoch, seine Not in eine Tugend zu verwandeln, indem er sich die literarische Tradition zum Trotz ,zur Quelle immer neuer Anregungen" (ebd.) machte. Seinen unverwechselbaren, durch erstaunliche, autoreflexive, sprachliche Virtuosität, hochartifizielle „Wortalchemie“ (Krättli 1984: 541) und lange Satzperioden gekennzeichneten Stil erarbeitete er sich, indem er sich zunächst entsprechende Sprachübungen anlegte, in denen er - wie die Maler die ,großen Meister ",kopierend ${ }^{6}$ - die Satzschemata solcher Schriftsteller wie u. a. Günter Grass, Robert Musil, Hermann Broch, Franz Kafka oder Thomas Mann mit eigenen Worten füllte und auf diese Weise „sich ausdrücken“ (Burger 1986: 74) trainierte. Ebenso hat er mit größter Lust an „der lachenden Perversiflage“ (Zumsteg 2011: 346) eine „Unsumme von Prätexten beim Schreiben“ eigener Werke auf eine 
solche Art und Weise verfertigt, dass sie „dabei im Mindesten an ,Originalität““ (ebd.: 351) einbüßen. Demzufolge sind seine Werke - um es mit Monika Schmitz-Emans zu sagen - ,als großangelegte werkübergreifende Replik auf mehrere Kerntexte der sprachphilosophischen und sprach-poetologischen Tradition" (Schmitz-Emans 2004: 67) zu lesen. Ein Kennzeichen der Werke Burgers ist aber neben dieser weitausgeprägten Zitathaftigkeit die Anwendung von höchst exakten, zugleich durchaus kuriosen Benennungen der Lokalitäten und Gegenstände, die vom Wort her erschlossen werden. Dies führt somit zu einem ausufernden Gebrauch von Fremd- und Fachwörtern, von überraschenden Neologismen und Sprachspielen sowie zur Gestaltung minutiöser, in ihrer Detailliertheit geradezu surreal wirkender Beschreibungen, die sich durch höchste Artifizialität und „fachliche Überpräzision“ (Burger 1986: 45) auszeichnen.

Diese Charakteristika prägen bereits Burgers ersten, überraschend eigenwilligen Roman Schilten. Schulbericht zuhanden der Inspektorenkonferenz (1976), der als ein überdimensionierter Rechenschaftsbericht eines skurrilen und pedantischen Dorfschullehrers an die Schulinspektion konzipiert ist, wobei dieser zu erklären sucht, warum er den Unterricht gänzlich zur Todeskunde umgewandelt hat. Das Buch strotzt geradezu von ungewöhnlichem Material: es enthält exakt formulierte Exkurse über den Instrumentenbau, über Turmuhrwerke und Postreglemente, über das Präparieren und Ausstopfen von Vögeln, über Friedhöfe und Friedhofsbräuche, über das Scheintotenwesen oder das Verschollenheitsverfahren. Ähnlich wie dieser Roman ist Burgers Meistererzählung Diabelli, Prestidigitateur. Eine Abschiedsvolte für Baron Kesselring (1979) als Rollenprosa angelegt, diesmal als ein Entschuldigungsschreiben eines Zauberkünstlers von internationalem Rang an seinen Mäzen, in dem er sprachbesessen mit den Wörtern jonglierend - von seiner Desillusionierung, seiner „Hokuspokuskrise“ (Burger 2002: 30), wortreich berichtet. Als ähnlich bizarre sprachliche Kunstwerke erscheinen die weiteren Bücher: In Die Künstliche Mutter (1982), einer ,tolle[n] Mischung von Hochschul-, Militär- und Ärztesatire, ein[em] Pandämonium von Eros- und Todesphantasien“ (Wysling 1996: 69), verwandelt der Autor im stark intertextuell geprägten Verfahren Autobiographisches in „Wortzauber" (ebd.: 78) und entfaltet in einer Vielzahl der von Fremdwörtern abgeleiteten, kalauerhaften und höchst kuriosen Wortschöpfungen richtige „Wortorgien“ (ebd.). So ist in diesem Roman die Rede u. a. vom ,euterwarmen Höhlenraum“ im „Granitschoß der Helvetia“ oder vom „mammalischen Matronengebirge" sowie von dem „Omnipatienten“, „Sexualnöter" und „Brestnam“ Schöllkopf, dessen Krankheit als „Multiple Matrose“ und die Therapie als „Mamamnese“ bezeichnet werden (Burger 1982: 43, 45, 164, 60, 148, 190). Die beiden ersten Teile der autobiographisch inspirierten Tetralogie Brenner: Brunsleben (1989) und Menzenmang (1992), die wegen des Freitodes des Autors unvollendet blieb, sind dagegen im Sprachregister der Tabakkunde gehalten, wobei aber viele der gebrauchten Ausdrücke auch der Medizin entstammen. Eine derartige Überladung der Sprache mit einer Fülle von stilistischen Eigentümlichkeiten verrät nicht nur, dass hier ein Germanist am Werk ist, sondern bezeugt zugleich das Misstrauen des Autors gegenüber einer konventionellen, ,realistischen' Sprache. Infolgedessen erscheinen die Werke Hermann Burgers ebenso als höchst artifizielle wie auch als bewusst sprachkritische Texte. Durch seine berauschende Sprachakrobatik und in bewusster Anknüpfung an Jaques Derridas Dekonstruktion hat nämlich der Autor auch immer eine Sprachanalyse betrieben: er jongliert mit Begriffen der Wissenschaft, der Philosophie und Literatur, doch zugleich mit 
neugebildeten Fremdwörtern und überraschenden Sprachwitzen, sodass dadurch die sprachlichen Strukturen einerseits hervorgehoben, andererseits aber ironisch überspielt werden. Infolge eines solchen Verfahrens tritt somit letztendlich der Inhalt der Werke hinter ihre sprachlichen Aspekte.

Den sprachlichen Experimenten ist auch das Werk Jürg Laederachs verpflichtet, eines der eigenwilligsten Sprachartisten in der Deutschschweizer Literatur und eines deklarierten Skeptikers gegenüber dem traditionellen Erzählen. Als einer „der bedeutendsten und raffiniertesten Exponenten literarischer Autonomie" (Mielczarek 1996: 32) hat der vor kurzem verstorbene Laederach - ähnlich wie Gerhard Meier, wenn auch auf seine eigene, spezifische Art und Weise auf den Spuren Robert Walsers wandelnd - in seinen hochreflexiven Büchern der literarischen Fiktion neue Impulse verliehen, indem er den ,Autonomieanspruch der Literatur [...] derart radikalisiert [...], dass der Erzähler einer Maschine zur Textproduktion ähnelt, die zwar Bedeutungen vermittelt, jedoch keine Ansprüche meldet" (ebd.). Seine Bücher kennzeichnen verschnörkelte, mäandernde, spiralförmige Sätze, die Hermann Burger einmal mit einer „Wendeltreppe“ (Burger 1984: 37) verglichen hat. Während aber seine rastlosen Wortimprovisationen ins Unüberschaubare wuchern, wird zugleich der frei assoziierte, extrem offene und abstrakte Redefluss entsprechend rhythmisiert, wodurch die Bewegungen der Sprache und die Form der Texte vor dem mitgeteilten Inhalt die Priorität gewinnen. Dies bezeugen auch solche Verfahrensweisen, in denen alle Fiktionen, die die Sprache aufbaut, in ständigen Wiederholungen und Variationen durch Sprache wieder abgebaut werden, sodass Sibylle Cramer Laederachs Texte als ,imaginäre Bühnen“ bezeichnet, „auf denen sich der Widerstreit zwischen Schreibakt und Tilgungsprozess abspielt" (Cramer 2001: 83). Diese Texte stützen sich auf keine Fabel oder Story, sondern die Handlung wird vor allem ,als Folie zur Erzeugung von Subtexten" (Weber 1995: 2) eingesetzt, wobei auch theoretische Überlegungen eine wesentliche Rolle spielen. Laederach brachte auf der Basis von Kombinatorik, Mathematik, Physik, Philosophie und Musik unterschiedliche Partikeln der Realität in die Textur seiner Werke hinein und bezog seine Sprache hellhörig aus vielen verschiedenen Sprachen, die er aneinander vorbeireden ließ und die er gleichzeitig in immer neuen überraschenden Zusammenhängen zu einem Netz kombinierte. Die Gestaltung seiner Texte bestimmt eine streng, errechnete' Beliebigkeit, wodurch sie im krassesten Gegensatz zur traditionellen Romanform stehen, die ja auf Kausalität und Kohärenz setzt und daher nach der Ansicht des Autors der empirischen, chaotischen Welt nicht mehr gerecht sein kann. In seinen Grazer Poetikvorlesungen Der zweite Sinn oder Unsentimentale Reise durch ein Feld Literatur (1988), die eine Einleitung sowohl in Laederachs eigene Texte als auch in die theoretischen Voraussetzungen experimenteller Literatur liefern, stellte der Autor fest, die „Literatur ist ein Chaos“ (Laederach 1988: 9), und er bekannte zugleich: „Ich will ja versuchen, aus der Ordnung Ihrer Vorstellungen Chaos herzustellen in Ihnen“ (ebd.: 10). Denn ihm zufolge wird die Welt als ein ,allgemein anerkanntes Chaos" (ebd.: 15) erfahren, und weil die Literatur eine Abbildung der Weltkonstitution liefern soll, sprach Laederach im Hinblick auf literarische Texte von verschiedenen „Chaoi“, die „erst hergestellt werden sollen“ (ebd.) und bei denen es genügt, das allgemeine Chaos mit sprachlichen Mitteln zu referieren. Dies geschieht bei ihm hauptsächlich dadurch, dass er freiem Assoziieren folgte und keinen Gedankenbruch scheute, dass er im Redefluss überraschende Wenden herbeiführte, die nicht nur des Lesers erstarrte Lesegewohnheiten erschüttern sollen, sondern auch dem Autor neue Erfahrungen 
bescheren. Zu sich selbst bekannte also der Schriftsteller: „Ich bin Chaotiker, ich bin Systematiker. Nur ein Systematiker weiß über das Chaos Bescheid.“ (ebd.: 14)

Jürg Laederach setzte sich somit zum Ziel, das Chaos der modernen Welt und des Sprachsystems in der literarischen Sprache abzubilden - in einer präzise unverständlich gestalteten Sprache, die sich selbst auflöst. Seine erzählerischen Mittel sind neben der freien Assoziation diverse ,Wiederholungstechniken, Kanon, Refrain, Reprise, Variation, Umkehrung, Überlagerung, Rotation, Steigerungsformen, vor allem aber Schwundformen“ (Cramer 2001: 83). Er experimentierte jedoch nicht nur mit der Sprache selbst, sondern auch mit allen literarischen Genres und Stilen, die er parodierte und demontierte. So erprobte er in seinem Debütband Einfall der Dämmerung (1974) in den unterschiedlichsten Sprachstilen und Erzählformen die Möglichkeiten der Kurzform. Dank einer ,quasi avantgardefilmischen Schnitt- und Montagetechnik“ (Weber 1995: 2), bei der Versatzstücke literarisch präformierter Wirklichkeiten miteinander kombiniert sind, werden hier Handlungen aufgelöst und in Einzelsätze zerlegt, während logische Abläufe durch nicht selten witzige Assoziationen ersetzt werden. Der Roman Im Verlauf einer langen Erinnerung (1977) ist dagegen auf der Formvorlage eines abenteuerlichen Reiseberichts geschrieben und bedeutet „vom Schlusswort ,Nichts ‘ gelesen die Umkehrung des Romans als Spielart des universalistischen Schöpfungsaktes“" (Cramer 2001: 83), wobei das Gelebte ausdrücklich in Sprache, in die erzählerische Reflexion umgestaltet wird. Der „Roman einer zertrümmerten Welt" (Weber 1995: 7) Flugelmeyers Wahn. Die letzten sieben Tage (1986), der entsprechend dem Untertitel in sieben Abschnitten die Abläufe einzelner Tage Flugelmeyers überfliegt, durchstreift und persifliert zugleich wohl alle möglichen Genres: vom Epos über die Reportage und Werbespot bis zur U-Bahn-Durchsage. Als Laederachs Opus magnum gilt aber der Roman Emanuel. Wörterbuch des hingerissenen Flaneurs (1990), dessen Formenvielfalt und eigenwillige, sich jeglichen Zusammenhängen verweigernde Textorganisation ihn ,zu einer angewandten Studie in Entropie“ (ebd.: 9) macht. Es dominieren hier atemberaubende, sprachwuchtige Reihungen und Häufungen von Sätzen, was der Schriftsteller in seinen Poetikvorlesungen als einen Zustand, ,höchster Entropie“ (Laederach 1988: $85)$ bezeichnete. In Passion. Ein Geständnis (1993) wird schließlich der sich in Wiederholungen, Variationen und Tautologien unaufhörlich dahinwälzende Text dermaßen zerhackt und zersplittert, dass er sich von jeder Stelle aus lesen oder weiterlesen ließe, ohne dass sich dem Leser der Inhalt erschließt, denn es gibt keine Abfolge von Geschehnissen und keine nacherzählbare Geschichte, keine Gefühle, kein Geständnis und keine Passion: Das Genre der Bekenntnisliteratur, mit dem Untertitel suggeriert, wird nämlich konsequent demontiert und die Wörter, die Gefühle bezeichnen, konstruieren nur ein perfektes Gefängnis der Gewohnheiten und Erwartungen, sodass die Passion in Wirklichkeit zum Leidensweg des Menschen in der modernen Gesellschaft wird.

Auf Laederachs literarische Variationen, die häufig nach außerliterarischen Ordnungsmustern strukturiert sind, hat sich insbesondere sein Interesse für die Jazz-Kultur anregend ausgewirkt. Demzufolge erscheint sein Buch 69 Arten den Blues zu spielen (1984), das auf dem Umschlag als eine „Enzyklopädie der Kurzgeschichte“ ausgegeben wird, als ein Kompendium verschiedener avantgardistischer Schreibmöglichkeiten. Man findet darin über siebzig Texte von verschiedenen Bauarten, Formen und Sprachstilen, diverse Erzählpassagen, tagebuchartige Eintragungen, Skizzen und surreale Arrangements, in denen der Autor bei Anwendung musikali- 
scher Techniken und insbesondere nach dem Vorbild einer Jazzimprovisation ein Thema aufgreift und es plötzlich wieder abbricht, um sogleich bei einem neuen anzusetzen. Bei den einzelnen Texten dieses Bandes, die von der Redundanz und der Variation strukturiert sind, also von der „,sprachliche[n] Umkreisung des Immergleichen" (Aeschbacher 1998: 332) und dem Austausch einzelner Partikeln innerhalb der Wiederholungen, handelt es sich um diverse Versatzstücke realer oder angelesener, vielfach gefilterter Wirklichkeit, die der Autor durcheinander schwirren lässt. Motive, Räume und Figuren widerlegen sich selbst, werden auseinandergeschlagen und neu montiert, die Sätze werden aufgesplittert und die Zusammenhänge zwischen den Wörtern zersägt. Um Geschichten im herkömmlichen Sinne handelt es sich somit keinesfalls, denn die dargebotenen Texte bilden keine bekannten oder möglichen Begebenheiten ab und bezeichnen auch nichts Vertrautes. Demzufolge zeigt sich in Jürg Laederachs sprachartistischen Experimenten - noch deutlicher als bei allen anderen Autoren - das Misstrauen der konventionalisierten Sprache gegenüber, denn ihr gewaltiger, exzessiver Sprachaufwand zielt vor allem darauf hin, das Vertraute in Frage zu stellen und an der vermeintlich feststehenden Ordnung zu rütteln.

\section{Satzarchitektur und Wortmusik: Zu Reto Hännys Prosawerken}

Vor diesem Hintergrund sind auch die Prosawerke Reto Hännys (geb. 1947) zu betrachten, des anderen ,sprachbesessenen' Sprachartisten der Deutschschweizer Gegenwartsliteratur und eines der ,wildesten und experimentierfreudigsten Schriftsteller unter seinen Zeitgenossen" (Bucheli 2017: 41), in dessen Werken wie etwa bei Jürg Laederach - der sich an Jazzvariationen wie auch überhaupt an diversen Musikstücken orientierende Sprachrhythmus und der melodische Sprachklang ausschlaggebend sind. Fast täglich hört Hänny Musik, oft mit der Partitur in der Hand, und feilt dann an seinen eigenen Texten so lange, bis aus Sprache Musik wird. Er lässt sich aber beim Schreiben auch von verschiedenen Bildern und Fotografien inspirieren, sodass insbesondere seine späteren Werke wie hochartifizielle, versponnene, musikalische Sprachbilder komponiert sind. In seinen bildstarken, reflexiv-sprachartifiziellen Texten entwirft somit Hänny nicht enden wollende Satzkonstruktionen mit kreisenden Wiederholungen, die weite Zeit- und Themenräume miteinander verknüpfen, sowie fließende und stürzende „Wortkaskaden“, in denen sich „die fremde und raue Schönheit dieser Sprache“ (Bucheli 2017: 41) offenbart. Daher schrieb Roman Bucheli zum 70. Geburtstag des Schriftstellers, Reto Hänny „malt und musiziert mit seiner Sprache, harmonisch und disharmonisch, konkret und kubistisch" (ebd.).

Mit seinen Werken erscheint somit der Schweizer Autor als ein besessener Sprachgestalter und Spracherfinder: Seine wuchernden und doch sorgfältig komponierten, rhythmischen Satzwindungen reichert er mit einer Fülle von bildhaften und lautmalerischen Ausdrücken an, bisweilen auch mit Neubildungen oder kraftvollen Helvetismen, die er aus dem ,Walserdeutschen“ (vgl. Guetg 1994), der Sprache seiner Kindheit, bezieht. Er scheut auch nicht davor, die syntaktische Ordnung zu zerstören, doch seine in die Breite fließenden Schachtelsätze, die der grammatischen und stilistischen Korrektheit zuwiderlaufen, sollen der komplexen Wirklichkeit gerechter werden und zugleich eingefahrene Sprachmuster und deren Linearität aufbrechen, um so dem Leser die Konstruiertheit der 
Sprache und ihre nicht selten die Wahrheit verschleiernde Wirkung bewusst zu machen. Sein poetologisches Programm formulierte also der Schriftsteller 1994 wie folgt:
Worum ich mich immer wieder bemühe, ist, die Sprache, oder die Sprachbilder, eindringlicher und präziser zu formulieren. Das ist ein Prozess, der nie zu Ende sein wird. Sollte ich je einmal an einen Punkt gelangen, bei dem an meinen Texten nichts mehr zu verbessern ist, werde ich aufhören. Mein poetologischer Ansatz ist kein einfacher. Ich will nichts anderes, als die Bilder derart stark machen, dass sie bei den Lesenden etwas auslösen, dass sie vielleicht ein bisschen uneins werden, weil nur noch das Uneins-Sein mit Dingen eine Überlebenschance bietet. Sätze verbessern heißt aber auch, sie schwieriger machen, damit sie weniger leicht ver- einnehmbar sind (ebd.).

Ein entscheidendes Kennzeichen der Prosawerke dieses Schriftstellers ist darüber hinaus ihre wuchernde Intertextualität, denn Hänny schöpft mit vollen Händen aus dem reichen Vorrat der literarischen Tradition, fügt seine eigenen Bücher aus einer Vielzahl anderer Bücher zusammen und webt in das Eigene Übernommenes so geschickt ein, dass daraus etwas völlig Neues entsteht. Daher bezeichnet er sich selbst als einen „Kopisten und Kompilator“, der ,,abschreibt und neu arrangiert, was andere vor ihm um ihr Leben erzählt und aufgeschrieben haben“" (ebd.). Jürg Laederach, dessen Werke ebenfalls eine stark ausgeprägte Intertextualität kennzeichnet, nannte Hänny einen „Zitierperfektionisten“ und bestimmte dessen Methode in dem viel diskutierten Werk HELLDUNKEL, das ausdrucksstark die technisch präzise begangenen Grausamkeiten der heutigen Welt beschreibt, wie folgt:

Die Kunst des Zitierens besteht bekanntlich unter anderem darin, Zitate aus ihrem Zusammenhang zu reißen und dem Zitator gefügig zu machen. Alle hier Zitierten, ob zeitgenössisch oder längstverstorben, deshalb so, als hätten sie Hännys Buch gelesen und seien zu einer Intervention veranlaßt worden. Dadurch entsteht der Eindruck, als benötigte Hänny Hilfskräfte, um dem grausamen Selbstlauf seiner Erzählung zu entgehen. Erst mit der Zeit erkennt man, daß die Inszenierung auch anders herum wirkt: Hänny, der Zitierperfektionist, findet immer wieder bei einem anderen Autor den treffendsten Satz zur Weiterführung der Erzählung, verleiht seinem Thema auf diese Weise eine alles-folternde, alles-vernichtende Gewalt, ohne es je selbst definieren zu müssen (Laederach 1994).

Es zeigt sich somit, dass für Hänny die Realität und die gesellschaftlichen und politischen Erscheinungen vordergründig sprachlicher Natur sind. Der Schriftsteller erschuf sich eine Sprache, die in ihrer artifiziellen und äußerst komplizierten Strukturierung gegen ein einlullendes Geschichtenerzählen gerichtet ist und vor allem einer adäquaten Erfassung der vielschichtigen, komplexen Wirklichkeit dient.

Reto Hänny debütierte 1979 mit dem Roman Ruch. Ein Bericht, dessen Titel zum einen die Umkehrung des Namens der schweizerischen Stadt Chur ist und zum anderen auch als Motto über sein gesamtes Schaffen stehen kann, denn mit „Ruch“, was so viel zu bedeuten hat wie ,Bewegung' oder ,Aufruhr', formulierte der Autor gewissermaßen sein ästhetisches und politisches Programm, demzufolge er die ver- 
meintlich feststehende gesellschaftliche Ordnung auf den Kopf stellt, ihr wahres Gesicht erbarmungslos entlarvt und sie auf diese Weise ,in Bewegung' setzt, $d$. $h$. in seinen Wortkaskaden sie und sich selbst von bisherigen Bindungen befreit. In diesem Buch kehrt der Autor nach Chur seiner Jugendjahre zurück, das er aber in der Umkehrung des Wortes gnadenlos verhöhnt und zur Karikatur einer spießigen Kleinstadt entstellt (vgl. Bucheli 2017: 41). Ruch ist demzufolge eine bissige Satire des helvetischen Alltags, die sich aus Vorgefundenem und Erfundenem, Erinnertem und Vorgestelltem zusammensetzt. Durch die Figur des namenlosen Protagonisten, der beim städtischen Theater in verschiedenen Funktionen arbeitet und es daher von der anderen, verborgenen Seite her - der des Staubs und des Verfalls hinter den Kulissen - zu sehen vermag, zeigt hier der Autor das Theater als eine Welt des Scheins, vor allem aber entlarvt er die Stadt selbst als ein Theater, in dem nicht nur die Menschen ihre verschiedenen Rollen spielen, sondern sogar die Natur lediglich zur Szenerie reduziert wird. Der in der dritten Person erzählende Romanprotagonist bezeichnet sich selbst als ,,berichterstatter“ (Hänny 1979: 10), doch gleichzeitig gibt er zu, er habe die ,bescheidene[...] absicht“, „für die langen winternächte“ eine Geschichte „,zu einem ruhigen einschlafen“ (ebd.) zu erzählen, was zu der suggerierten Form des Berichts im krassen Kontrast steht. Entsprechend diesen gegensätzlichen Absichten des Erzählers schwankt das Erzählte stets zwischen Fiktionalem und Nicht-Fiktionalem, zwischen sich sachlich und objektiv präsentierenden Passagen und subjektiven Visionen des ,Berichterstatters', der allmählich selber in Verwirrung gerät und schließlich bekennt:

[...] selbst wenn für einen der vorsatz REKAPITULIEREN STATT ERFINDEN ANTWORTEN STATT DARSTELLEN gälte, wüßte man am ende nicht mehr mit sicherheit zu unterscheiden, ob man nun etwas zusammenfabulierend träume oder sich untrüglich erinnere oder beides in einem, aber vielleicht wäre dies ohnehin das gleiche, etwas betrachtend erinnere man sich an vergangenes, weit zurückliegendes [...], wobei das betrachtete unversehens das erinnerte zu beeinflussen begänne, lenkte, färbte, ebenso wie umgekehrt: die erinnerungen wucherten, dehnten sich, zerfaserten, das betrachtete verschwömme, bis man meinte, eben noch feststehende dinge wären verrückt worden [...] (Ebd.: 218-219).

Dem Erzählenden zerfällt die Welt zunehmend in Fragmente und unbedeutende Details, sodass er nicht mehr imstande ist, die Wirklichkeit in den Griff zu bekommen und ihre Komplexität sprachlich wiederzugeben. Was der Roman letztendlich präsentiert, ist somit keineswegs eine Gute-Nacht-Geschichte, sondern die „Demontage von Geschichte“ (Moser 1991: 3): In einem Labyrinth von weitausschweifenden Sätzen, von detaillierten Ergänzungen und ,langwierigen langweiligen abschweifungen / abschweifungen von abschweifungen“" (Hänny 1979: 97) führt hier der ,Berichterstatter" einen Kampf gegen die Sinndefizite in allen Bereichen des gesellschaftlichen Lebens, gegen das gesellschaftliche Rollenspiel und die Welt des Scheins, gegen die Sinnlosigkeit der alltäglichen Reden, die in der gleich zu Beginn des Romans angeführten Erzählung Gestalt annehmen. Da bekennt nämlich der Protagonist, dass er „zu jeder beliebigen tages- und nachtzeit“ (ebd.: 11) allerlei Leute anruft, um sie „,mit irgendwelchen, ihm gerade einfallenden sätzen zu überschütten, oder sobald sich beim gegenüber am draht die erste verwirrung geklärt gelegt hat, von diesem, nun sichtlich in erregung geraten, aufgebracht, sich bald einmal selbst 
durch gehässigte telefonsatztiraden überschütten zu lassen“ (ebd.: 12). Seine Anrufe, die keiner Informationsvermittlung dienen, stellen Rosmarie Zeller zufolge „ein Abbild des sinnlosen Geredes der Welt dar, welches wiederum der Gegenstand des Romans ist" (Zeller 1992: 109). Um in dem ununterbrochen produzierten ,wörtersee“ „,nicht schwimmuntüchtig sprachlos [...] zu ersaufen“ und „gegen die wortflut an[zu]schwimmen“ (Hänny 1979: 112), muss also der Erzählende „weiterfahren, wie wenn nichts wäre / wie wenn nichts wäre unbeirrt fortfahren / trotz unlust und überdruß, aller widersprüchlichkeit, aller müdigkeit zum trotz". So erzählt er ständig weitere Geschichten, verzettelt sich in ihnen, und sein ununterbrochen vorwärtsflieBender und jeder Assoziation folgender Redefluss artet bisweilen in reine Sprachspielereien aus, die allerdings nicht selten zu einem entlarvenden Ergebnis führen, wie etwa an folgender Stelle:

[...] postplatz heldenpark heldenplatz heldenhof heldenwinkel heldentor heldenplatz,

ordentlicher,

heldenwinkel heldengäßchen heldengraben heldenallee heldenquai heldensteig heldentor heldenpark heldenpalast heldengrab, helden, gräber [...] (Ebd.: 95).

Als dominierende Stilmittel dieser Prosa stellte Hermann Burger die „Redundanz und Aberranz (Abirrungstechnik)“" (Burger 1984: 37) heraus, mit denen der Autor die grammatische Korrespondenz der Satzglieder zerstört, das Erzählte ins Leere laufen lässt und in rhythmisch dahinfließenden Wortkaskaden seinen Wirklichkeitsschilderungen den Sinn verweigert. Aber gerade dadurch schreibt Hänny gegen die Sinnlosigkeit der Realität an, denn indem seine literarischen Sätze nicht so reibungslos ablaufen wie z. B. jene im Theater, die schon ,aller widerborstigkeit verlustig gegangen“ (Hänny 1979: 222) sind, bekommen sie ihren Stachel zurück und können so gegen das öffentliche Geschwätz aufkommen. Durch seinen ungewöhnlichen und gewagten Sprachstil konfrontiert somit der Autor den Leser ständig mit der Frage, wie denn unsere komplexe, nicht mehr zu überblickende, sinnlose und chaotische Realität sprachlich wiederzugeben sei, ohne in die üblichen sprachlichen Raster zu verfallen.

Bereits in diesem Erstling offenbarten sich die für Hännys Schreiben so charakteristischen Verbindungen von „Geschichte und Politik, Vergangenheit und Gegenwart, Allgemeine[m] und Private[m]“ (Moser 1992: 2), also das Berichten von „Ereignissen, die ihn zum Beteiligten machen“, was Samuel Moser folgendermaßen kommentiert:

Die Chronologie der Ereignisse verschwindet mit dem Aufbrechen des geradlinigen Erzählens. Die Prosa weitet sich ins Unüberschaubare. Ein immenses, der Disharmonie verpflichtetes Orchester von Sätzen spannt weite und weiteste Bogen. Mit der Darstellung eines Gegenstandes gelangt zugleich die Darstellung selber zur Darstellung. Die Unterscheidungen von Fiction und Non-Fiction, Subjektivität und Objektivität verlieren ihren Sinn. Hännys Subjektivität ist nichts anderes als am eigenen Leib erfahrene Objektivität (Ebd.).

Diese Charakteristik trifft insbesondere auf die beiden weiteren Bücher des Schriftstellers zu: den autobiographischen Bericht Zürich, Anfang September (1981), in dem 
Hänny sowohl die Genese der sog. ,Zürcher Krawalle ${ }^{2}$ als auch seine eigene Verhaftung, Verprügelung und Ohnmacht gegenüber der Staatsgewalt ausführlich beschreibt, sowie die Aufzeichnungen seiner Polenreise Am Boden des Kopfes. Verwirrungen eines Mitteleuropäers in Mitteleuropa (1991), in denen die Auseinandersetzung mit der Staatsgewalt in der demokratischen Schweiz in Verbindung mit den Schilderungen des kommunistischen Polen fortgesetzt wird (vgl. Sośnicka 2015). In diesem von Reflexionen überladenen Reisebericht, dessen Titel und Motto ein Zitat aus Zbigniew Herberts Gedicht „Alltag der Seele“ aus dem Band Herr Cogito (1974) bildet, dokumentiert der Schriftsteller seine dreiwöchige Polen-Reise im Oktober 1989, die er als „Reisender in Sachen Literatur aus einem wahrscheinlich doch recht fernen, randständigen Land, das sich aus der Geschichte ausgeklinkt hat" (Hänny 1991: 9), absolvierte. Von polnischen Germanisten der besuchten Universitäten über die polnische Geschichte und Gegenwart unterrichtet und die polnischen Realien nach der Wende und nach den ersten freien Wahlen im Juni 1989 beobachtend, zugleich aber die aktuellen Entwicklungen in der DDR registrierend, die schließlich zum Fall der Berliner Mauer führten, informiert hier Hänny über den Zusammenbruch des Kommunismus, aber auch über die Zustände im früheren kommunistischen Polen und setzt diese dem $\mathrm{Zu}$ sammenbruch der Demokratie in Zürich gleich, indem er u. a. den Mord an dem oppositionellen Priester Popiełuszko mit der eigenen Verhaftung in den ,Zürcher Krawallen " parallelisiert. Da ihm aber verschiedene polnische Missstände auch nach der Wende nicht entgehen, schlägt er schließlich spöttisch vor, zwischen Polen und der Schweiz eine Art Joint Venture zu gründen, weil - wie er hervorhebt - beide Länder im „Selbstfeiern des Sonderfalls“ (ebd.: 233) besonders geübt sind, außerdem trügen „beide die gleichen Nationalfarben [...], nicht von ungefähr die von Blut und Schnee“ (ebd.), was ihn zu dem stichelnden Vorschlag veranlasst, auch eine gemeinsame Nationalflagge und ein Staatswappen entstehen zu lassen: es „,bräuchte dem Adler nur das gemästete Kreuz unterzuschieben“" (ebd.: 234). Trotz ausführlicher Behandlung diverser Ereignisse aus der polnischen Geschichte und Gegenwart dominieren somit in diesem Reisebericht helvetische Themen. Ähnlich wie in Zürich, Anfang September reflektiert hier Hänny sein Selbstverständnis als Schweizer und demontiert zugleich die Idylle Schweiz grundsätzlich, indem er das Musterland der Demokratie als ein Land mit Krawallen, Skandalen und anderen Problemen entlarvt.

Als eine Anti-Idylle erscheint auch Hännys Roman Flug (1985), der ein Erinnerungs- und Traumbuch, eine gesellschaftliche Satire und literarische Geschichte der Fliegerei in einem ist, wobei die Flugmetapher ebenso für die ausschweifende Phantasie steht wie auch die drei Erzählebenen des Romans miteinander verknüpft, ja, gewissermaßen sogar den Bau dieses Werkes bestimmt, was Samuel Moser folgendermaßen erläutert:

Anders als der Erstling Ruch, in dem Reto Hänny sich am Schreiben zum Schreiben brachte (sich einem unaufhaltsamen, obgleich immer wieder versiegenden Sprachfluß überlassend, dessen Quelle er selber war), hat Flug den harmonischen Körperbau eines Vogels. Zwischen Anfang und Ende, den beiden doppelt gefieder-

Als ,Zürcher Krawalle“ oder ,Opernhauskrawalle“ werden die Jugendunruhen in der Schweiz in den 1980er Jahren bezeichnet, die am 30./31. Mai vor dem Opernhaus in Zürich ausgelöst wurden. Der Zürcher Stadtrat genehmigte damals 60 Millionen Franken für die Renovation des Opernhauses, lehnte aber zugleich die Forderungen nach einem autonomen Jugendzentrum ab. Dies führte zu großen Protestaktionen der Jugendlichen nicht nur in Zürich, sondern auch in anderen Städten, in die die Polizei mit brutaler Gewalt eingegriffen hat. 
ten Schwingen, die sich (je geteilt in einen historischen und einen aktuellen Teil) der Aviatik widmen, hängt der Hauptteil mit seinem das Jazz-Intermezzo einklammernden, wiederum zweiteiligen Bericht, der die Jugend im Bergdorf und die Zeit als Mittelschüler in Ruch einander gegenüberstellt (Moser 2007: 250).

Den erzählerischen Rahmen bildet hier also ein Flug über die Alpen, den der Erzählende unternimmt, um die Schweiz aus Distanz zu beobachten. In kurzen Szenen überblickt er gleichzeitig die Geschichte der Aviatik und des damit verbundenen technischen Fortschritts, den er aber mit der militärischen, zerstörerischen Nutzanwendung der Fliegerei konfrontiert. Vor allem aber führt das Buch in die erinnerte Kindheit zurück und bekundet dabei - entsprechend dem als Motto angeführten Hölderlin-Zitat - den Wunsch, aus der „bleiernen Zeit“ (Hänny 1985: 7) ins Offene zu gelangen: aus der Enge des dörflich-ländlichen und später des bürgerlichen Lebens $\mathrm{zu}$ entfliehen. Durch das Kontrastieren der Erinnerung an die glückliche Kindheit mit dem Wissen um die Zerstörung Europas um die helvetische ,Insel ' herum setzt sich der Autor gleichzeitig mit dem Problem der Wirklichkeitsdarstellung auseinander. Wie trügerisch diese sein kann, präsentiert er, indem er in seinem Roman Postkarten und Filme thematisiert, anhand derer gezeigt wird, wie sie die ,wahre 'Wirklichkeit verdecken. Sein Ich-Erzähler beschreibt also u. a., wie er als kleiner Junge Amerika ausschließlich aufgrund der Postkarten von Tante Berta wahrgenommen hat und wie sein Amerika-Bild von diesen Postkarten geprägt wurde (vgl. ebd.: 7983). Besonders aufschlussreich sind dabei jene Passagen, in denen der Erzähler eine dieser Postkarten bis ins kleinste Detail beschreibt, und zwar so, als hätte er kein Bild, sondern die Realität selbst vor Augen. Die Beschreibung hört erst auf, als sich herausstellt, dass sich „alle weiteren Details, alle weiter vermuteten Feinheiten“ (ebd.: 36-37) - „durch eine Lupe betrachtet“ (ebd.: 36) - „,in grobe Rasterpunkte“ (ebd.: 37) auflösen. So kann die Beschreibung dieser Postkarte als eine Metapher für den Schreibprozess und die sprachlich nicht erfassbare Wirklichkeit gelten (vgl. Zeller 1992: 55), was auch die folgende Aussage des Autors bestätigt:

Die Welt ist glücklicherweise viel komplizierter, als es eine simplifizierende Grammatik oder Syntax wahrhaben will. Ich kann diese Welt nicht mit Sätzen wie „Subjekt, Prädikat, Objekt“ erklären. Was täglich an Bildern über uns ausgeschüttet wird, ist von einer derartigen Komplexität, dass mir nichts anderes bleibt als der Versuch, sie nachzuempfinden. Deshalb entstehen Texte, die so vielschichtig daherkommen (Guetg 1994).

Flug erklärte Reto Hänny zu seinem Lieblingsbuch, zu dem er zwanzig Jahre später zurückkehrte und es ,übermalte', wie auch Maler ihre Bilder übermalen. In der neuen Fassung von 2007 hat der Schriftsteller das frühere Werk vielfach umgestaltet, er kürzte es und beschleunigte das Tempo, er verlieh also dem Buch einen anderen Rhythmus, so dass es eine neue Gestalt gewann und zu einem neuen ,Flug' in die Kindheit zurück und in die Literatur hinein wurde. Im Nachwort zu der neuen Ausgabe fasst Samuel Moser die wesentlichen Unterschiede zwischen der früheren und der neueren Fassung wie folgt zusammen:

Daß Reto Hänny den Flug neu geschrieben hat, kommt einem neuen Flug gleich. Das liegt in der Konsequenz seines poetologischen Selbstverständnisses, das jeden 
Text als Text aus Texten und das Schreiben als die Heimkehr ,ins Offene“ versteht, von dem Hölderlins vielzitierte Gedichtzeile spricht. [...] Um den Text zu lichten, ihm mehr Zug zu geben, ihn leichter, transparenter (flugtauglicher) zu machen [...] hat er Strukturen und Schwerpunkte freigelegt wie etwa die Thematik der Textgenese und Autorschaft. Hinzugefügt hat er Passagen, die zeigen, was ihm seit dem ersten Erscheinen 1985 wichtiger geworden ist: der Lehrer Cla zum Beispiel, der ihn zum Leser und Schriftsteller hat werden lassen. Und er hat den Rumpf seines „Vogels“ sichtbarer gemacht: die Kindheit am Berg und die Jugend in der Stadt (Moser 2007: 257-258).

$\mathrm{Zu}$ Recht hebt hier Samuel Moser sowohl die früheren als auch die neuen Gewichtungen im Schaffen Reto Hännys hervor, denn diese haben des Schriftstellers zwei weitere wichtige Werke hervorgebracht: Das Gedenken seines Lehrers, des rätoromanischen Schriftstellers Cla Biert, führte zur Entstehung von Blooms Schatten (2014), einem Werk, das 2015 mit dem Schillerpreis der Zürcher Kantonalbank ausgezeichnet wurde; und das poetologische Selbstverständnis brachte bereits 1994 das sprachlich und kompositorisch höchst ungewöhnliche „Bilderbuch“ HELLDUNKEL hervor, für welches dem Autor - als einem „Analytiker der Poesie“"3 - der renommierte Ingeborg-Bachmann-Preis verliehen wurde. Beide Werke, Flug und HELLDUNKEL, verbindet dabei etwas, was Samuel Moser im Hinblick auf die beiden Flug-Versionen als „Ausdruck der Erfahrung des Lebensbedrohlichen in jeder Form“ (Moser 2007: 251) betrachtet; gleichzeitig betont er, dass Hännys Flug ,,auch von einer Geburt [berichtet]: der Geburt seiner Sprache aus der Musik" (ebd.), was für die Entstehung sowohl von HELLDUN$K E L$ als auch Blooms Schatten ebenfalls von gravierender Bedeutung war.

Das „Bilderbuch“ HELLDUNKEL ist ähnlich wie Flug ein Versuch, die Welt anhand von Bildern einzufangen, diesmal dienten aber dem Schriftsteller die Fotografien von Hans Danuser aus dem Zyklus IN VIVO als „Text-Generatoren“ (Hänny 1994: 177), die ihn zu eigenen Sprachbildern animierten. Es handelt sich also bei diesem „Bilderbuch“ um sprachliche Transformationen von Fotografien, die ,einen in bedrohliche, verdrängte Tabu-Zonen unserer Zivilisation entführen, Zentren des Wissens und Verbergens, Bereiche, die Tausenden täglicher Arbeitsplatz sind" (Hänny 2008: 1) und deren Existenz trotzdem allgemein verschwiegen wird, und zwar: Atombunker, technische Labors, labyrinthische Flure von Forschungsinstituten oder medizinische Sezierräume. Auf Hans Danuser verweist bereits der mehrdeutige Titel dieses „Bilderbuchs“, denn HELLDUNKEL bedeutet nicht nur einen ,Wechsel von Licht und Schatten“ sowie die „Dämpfung und Betonung von Tönen in Komposition oder Aufführung musikalischer Werke“ (ebd.: 2), sondern es sind in diesem Wort zugleich die Initialen des Fotografen und ebenso des Autors selbst versteckt, der sein Buch als „die Auseinandersetzung des Schriftstellers (Logotechnikers) H mit den Bildwelten des Photographen (,Lichtschreibkünstlers') D ..." (ebd.) versteht. Aber überhaupt spielen Buchstaben in diesem Buch eine entscheidende Rolle, denn auch ihre graphische Beschaffenheit, ihre Bildlichkeit war dem Autor ein wichtiger Impuls beim Schreiben. Er betont nämlich, dass ,,radikal gesehen“ (ebd.: 1) alle Schriftzeichen jeweils ein Bild für sich seien, indem sie sich ,aus einfachsten graphischen

3 So wurde Reto Hänny von der Jurorin Verena Auffermann bezeichnet. Vgl.: „Ingeborg-Bachmann-Preis 1994. Material zu: Reto Hänny: GUAI. Auszüge aus den Diskussionen der Jury“, PDF (eigene Materialien des Autors), S. 5. 
Elementen zusammensetzen: Senkrechte, Waagrechte, Schrägstrich und Back-Slash, Kreis (oder Kreissegment): $\mid-\wedge \mathrm{O}^{\prime \prime}(\mathrm{ebd}$.). In diesem Sinne bietet das „Bilderbuch" keine Abbildungen und keine Bildbeschreibungen im üblichen Sinne, sondern es ist vielmehr ein Buch über Bilder und mit verschiedenen Sprachbildern, eine Collage aus eigenen Sätzen und fremden Zitaten, mit der die „Unorte der Zivilisation" (Rüedi 1994: 87) festgehalten werden und die zugleich dem Leser die Unvermeidlichkeit des Todes vor Augen führt. Denn alle Sprachbilder, die Hännys „Bilderbuch" enthält, laufen letztendlich auf dasselbe hinaus: auf den Tod, den keine Wissenschaftlichkeit überwindet. Daher dominieren in dem Buch Bilder des Tötens und Sterbens: die aufgebahrte Leiche der Großmutter, Leichen auf Schlachtfeldern und bei Naturkatastrophen, Hinrichtungen und Malträtierungen, Vergewaltigungen und Sezierungen, menschliche Körperteile und Organe - ein aus dem Schädel gehobenes Hirn, ein herausgeschnittenes menschliches Herz, ein vom Körper abgetrenntes weibliches Bein mit teilweise entfernter Haut, eine männliche Leiche -, aber auch eine sezierte Laborratte oder eine mit Chromsäure vergiftete Fliege, die neben einem ,in Auflösung begriffenen Leib“ (Hänny 1994: 60) auf der Tischplatte zappelnd verendet und in deren Bild sich das unabwendbare Gesetz alles Kreatürlichen grausam verdichtet. Hinzu kommen kalte und abweisende Räume oder vom stürmischen Regen heimgesuchte Straßen, menschenleere Örtlichkeiten, in denen die Apokalypse gegenwärtig wird: ,Verheerte Landschaft, ausgeglüht, vergilbt, Stein geworden, [...] alle Farben ausgeblendet [...]" (ebd.: 173). Demzufolge tauchen am Ende nur noch „die in schwarzen Sand geritzten tiefschwarzen Zeichen“ auf, die sich wie hieroglyphische Figuren präsentieren - „fremd und schön wie die Palen einer versunkenen rätselhaften Kultur" (ebd.: 174).

In diesen exakten, kühlen und abweisenden Sprachbildern verschwindet das Subjekt fast gänzlich, es wird von einer wandernden Kamera abgelöst, nur ab und zu meldet sich zu Wort ein anonymer, Reisender', der die sterilen Räume und perfekten Apparaturen beobachtet und sie präzise beschreibt oder sie mit eigenen Erinnerungen und Assoziationen konfrontiert. Schmerzlich vermisst man also in all den Bildern den Menschen, der in Hännys „Bilderbuch“ lediglich als Sezierungsobjekt erscheint, beziehungsweise nur noch als „ein Druckfehler, den man übersehen hat und der einen im übrigen völlig klaren Text verwirrt" (ebd.: 139). Doch ausgerechnet ,in der Beschreibung der Abwesenheit von Leben“ wird in diesem Buch „das Leben beschworen“ (Rüedi 1994: 87), denn angesichts der kühlen und sachlichen, die ansonsten sorgfältig verschwiegene Wirklichkeit registrierenden Bilder Danusers ist dieses Leben „nur noch als Abwesenheit zu beschreiben oder als ein Schwinden“ (ebd.). Daraus eben bezieht Hännys Sprache ihre erschreckende Wucht; das eigentliche Anliegen des Autors ist es hier nämlich, „das Antoben von Sprache gegen die Statik der Bilder“ (ebd.) suggestiv wiederzugeben und zugleich die Möglichkeiten der sprachlichen Wiedergabe von Bildern sowie überhaupt das Funktionieren von Bildern und von der Sprache metareflexiv und intertextuell zu diskutieren. Der Schriftsteller schuf hier eine äußerst konzentrierte, ungeheuer intensive, statische Gegenstände plastisch und minutiös schildernde Sprache, die sich in mäandrischen, präzise konstruierten und syntaktisch äußerst komplizierten Schachtel- und Kettensätzen rhythmisch fortbewegt. Eine noch gröBere Steigerung der sprachlichen Artistik ist kaum vorstellbar, in Helldunkel erreichte Hänny wohl den Höhepunkt selbstgenügsamer Sprachbewegung und Sprachbildlichkeit. 
Einem ähnlichen Anliegen entsprang auch das zur Zeit letzte Buch Reto Hännys Blooms Schatten (2014), das der am Ende des Buches angebrachten „Anmerkung“ zufolge, ,wie jeder dichterische Text, nicht mehr und nicht weniger als ein klangverliebtes Spiel mit Lauten“ (Hänny 2014: 144) zu verstehen ist, indem der Autor mit den sprachlichen Zeichen „wie mit Tönen“ arbeitete, damit „,das erzählte Abenteuer im Abenteuer des Erzählens aufgeht" (ebd.: 145). Dieses in einem sich über 139 Seiten hindurchwindenden Satz erzählte Abenteuer setzt folgendermaßen ein:

Die Odyssee eines Annoncenakquisiteurs weder ohne Furcht noch ohne Tadel, der, teils unter Schock, von morgens um acht all die Stunden bis weit über Mitternacht hinaus, das nimmer Neue mit immer neuer Hoffnung zu betrachten, einen hektisch anstrengenden Tag lang [...] durch das Labyrinth einer Stadt weit oben auf der nördlichen Halbkugel irrt, wo [...] (Ebd.: 9).

So ist Blooms Schatten, dieses kompositorisch äußerst präzise, absolut radikale Sprachkunstwerk, ein dichterisch-musikalisches Spiel, mit dem der aus der oralen Tradition schöpfende Jahrhundertroman Ulysses von James Joyce in einem einzigen, stark rhythmisierten und in verschiedenen Tönen erklingenden Satz rekonstruiert wird. Freilich ließ sich in diesem einen, auf 139 Seiten mäandernden Satz nicht der gesamte, 1000 Seiten umfassende Roman erfassen - große Stücke des Ulysses wurden ausgelassen, was graphisch mit mehreren nur teilweise beschriebenen oder nur ein kleines Satzfragment aufweisenden Seiten markiert wird. Auf diese Weise realisierte aber Reto Hänny wortwörtlich seine Devise, der er sich schon seit seinen literarischen Anfängen verschrieben hat, dass nämlich Literatur immer aus Literatur entstehe (vgl. ebd.: 143). Daher wurde in Blooms Schatten nicht nur der Ulysses rekonstruiert, sondern in Hännys mit Sprachmusik erklingendem und syntaktisch ausuferndem Satz wurde auch anderes, absichtlich ,unverändert Übernommene[s]“ eingeflochten - ,vom Alten Testament über die Odyssee bis zu Shakespeare, Flaubert, Claude Simon, Juan Goytisolo und andern, bewusst zahlreiche fremde Dinten und Farben" (ebd.: 144).

Die Idee, den Ulysses neu, auf seine eigene Art zu schreiben, keimte in Reto Hänny schon auf, als er mit fünfzehn Jahren das Buch zum ersten Mal gelesen hatte. Damals verordnete ihm sein neuer Klassenlehrer in der Sekundarschule, der rätoromanische Dichter Cla Biert, als Mittel gegen die Legasthenie Bücher zu lesen: Die Blechtrommel von Günter Grass und den Prozess von Franz Kafka, aber auch den Ulysses von James Joyce, der damals in der Bischofsstadt Chur, wo er zur Schule ging, auf dem Index stand (vgl. Caflisch 2015: 14). Die Lektüre hat gegen die Legasthenie zwar nicht sofort geholfen, aber sie erweckte in dem Sekundarschüler die „Neugierde für die Wunderwelt der Sprache“ (Hänny 2014: 143) und ließ damit auch den Wunsch entstehen, Leopold Bloom mit eigener Sprache zu folgen, der nach vielen Jahren und nach längeren Musikstudien in Blooms Schatten Gestalt angenommen hat. Und so folgt Hännys Erzähler in diesem Buch dem Annoncenakquisiteur Leopold Bloom tatsächlich wie ein ,Schatten', von acht Uhr morgens bis ,,weit über Mitternacht hinaus“ (ebd.: 9), von zu Hause und der Küche in die Schlachterei, wo er sich eine Niere besorgt, treppauf zu seiner fremdgehenden Opernsängerin Molly, „seiner die Schlaftrunkene mimenden heißblütigen prima donna“ (ebd.: 24), und dann von zu Hause über die Straßen Dublins zum Postamt und ,musikvernarrt [...], auf einen Sprung in die Kirche“ (ebd. 39), in die Drogerie, um Seife zu kaufen, und 
dann in das öffentliche Badehaus, zur Teilnahme an einer Beerdigung und ins Zeitungsbüro, in den Lesesaal der National-Galerie, wo er ,in Folianten blättert, [...] umschwirrt von Geistesblitzen fürchterlich gelehrten Gedröhns, eingesargter Gedanken von Shakespeare \& Co.“ (ebd.: 61), später folgt noch ein Gang zum Strand und ein kurzer Besuch im Bordell, und immer wieder macht Bloom zur Entspannung auch einen Sprung in die Bars und die Pubs, bis er spät in der Nacht, vom Alkohol berauscht, „auf Zehenspitzen das Haus betritt“ (ebd. 117) und sich im „milchig bleich durch Gardinen schimmernden Morgendämmer“ (ebd.: 135) zu seiner Molly ins Bett legt, ihr noch ,in großen Zügen fein säuberlich den verflossenen Tag rekapituliert, um schließlich, ist auch dieses letzte Abenteuer gemeistert, ermattet zur Seite gesunken, [...] umströmt von feuchter wohliger Wärme, als Sehfrager im Sinnbad Sindbad dem Seefahrer nachsinnend und Tindbad dem Teefahrer und Windbad dem Wehfahrer und all den andern, die da waren und noch kommen werden, hundsmüd in den wohlverdienten Schlaf zu entschwinden, auf Traumflügeln - wohin?“" (ebd.: 136-137). Dieser eine literarische Satz, der von einem gewöhnlichen Tag eines gewöhnlichen Menschen erzählt und dessen mäandernden Bewusstseinsstrom in wechselnden Tempi fließen lässt, ist - wie Joyces Ulysses, der ,mit den technischen Mitteln der Musik geschrieben“(J. Joyce, zit. nach: Doderer 1996: 155) wurde - völlig ungewöhnlich, wenn auch auf seine ganz eigene, spezifische Art und Weise: Er ist Rhythmus und Wortmusik, die in der labyrinthischen Syntax und den vielfältigen Wiederholungen, dem sich einmal beschleunigenden und einmal retardierenden Sprachtempo, den unzähligen Alliterationen, Assonanzen und Paronomasien, den langen, wohlklingenden Vokalen und den hart erschallenden Konsonanten ertönt. In Blooms Schatten zeigt sich der Schriftsteller wie ein wahrer Sprachmusiker, der in seiner Musiksprache die Welt erklingen lässt, kompromisslos und abseits jeglicher Moden und Erwartungen die eigenen Ziele verfolgend.

Auch mit diesem Buch blieb somit Reto Hänny seinem literarischen Credo treu: Sprachbewusst und sprachkritisch, doch dabei auch sprachverliebt schöpft er aus dem vollen Vorrat der Literatur und lässt in seinen Texten die Bezüge zwischen Eigenem und Fremdem erklingen, wodurch alte Töne und Bedeutungen sich mit neuen gegenseitig potenzieren und ganz neue Schwingungen erzeugen. Ein Markenzeichen seines literarischen Stils ist zugleich seine komplexe, assoziativ ausgreifende, vielfach verschachtelte Satzarchitektur, sein „Bandwurm-, Ketten- oder Schachtelsatz [...], dem sich die Lesegewohnheit anpassen muss“" (Burger 1980: 342), der aber beim aufmerksamen Lesen seine eigene Musik offenbart. Mit all seinen gar nicht einfachen und durchaus ungewöhnlichen, von „der Architektur des Aufbaus, Musik der sprachlichen Kadenz“ und der „Leuchtkraft der Bilder“ (Doderer 1996: 168) getragenen Prosawerken beweist somit Reto Hänny, dieser ,zauberhafte[...] Verwandlungskünstler" (Bucheli 2017: 41), immer wieder und immer aufs Neue, welch große Potenziale der poetischen Sprache innewohnen, indem er radikal und ,abseits aller Sentimentalität das geschriebene Wort wieder in seine künstlerischen Rechte einsetzt“" (Linsmayer 1994).

\section{Literaturverzeichnis}

Aeschbacher, M., Vom Stummsein zur Vielsprachigkeit. Vierzig Jahre Literatur aus der deutschen Schweiz (1958-1998). Bern; Berlin; Frankfurt am Main [u. a.]: Peter Lang 1998. 
Bucheli, R., «Ein Dichter hat mehr als ein Leben», Neue Zürcher Zeitung, 13.04.2017, 41. Verfügbar über: https://www.nzz.ch/feuilleton/reto-haenny-ein-dichter-hat-mehr-als-einleben-ld.784267 [16.04.2018].

Burger, H., Diabelli - Blankenburg. Erzählungen. Zürich: Ammann Verlag 2002.

Burger, H., Die allmähliche Verfertigung der Idee beim Schreiben. Frankfurter Poetik-Vorlesung. Frankfurt am Main: S. Fischer 1986.

Burger, H., Die Künstliche Mutter. Roman. Frankfurt am Main: S. Fischer 1982.

Burger, H., «Theatralische Sendung in Chur. Reto Hännys Bericht ,Ruch“», Schweizer Monatshefte 60 (1980), 339-342.

Burger, H., «Vom Wandtafelsatz zur Polypenkonstruktion. Wie sich die Entwicklung der jüngeren Schweizer Literatur an der Satzbildung ablesen lässt», Tagesanzeiger, 21.06.1984, 37-38.

Caflisch, E., «Wie es kommt, dass ,Blooms Schatten“ bis zum Beverin reicht», Bündner Woche, 8.07.2015, 14.

Cramer, S., «Nenn mich bedingungslos Laederach. Ein emsig wirtschaftendes Paradox: der Autor Jürg L.», Neue Zürcher Zeitung 58, 10./11.03.2001, 83.

Doderer, H. von, Die Wiederkehr der Drachen. Aufsätze / Traktate / Reden. Vorw. von Fleischer, W. H. Hrsg. von Schmidt-Dengler, W. 2., durchgesehene Aufl. München: Beck 1996.

Guetg, M., «Versuchen, die Welt mit Sprache nachzuempfinden. Gespräch mit Reto Hänny», Bündner Zeitung, 3.08.1994.

Hänny, R., «Literatur ist Subversion. Interview mit Reto Hänny», Drehpunkt 50 (1981), 5056.

Hänny, R., Am Boden des Kopfes. Verwirrungen eines Mitteleuropäers in Mitteleuropa. Frankfurt am Main: Suhrkamp 1991.

Hänny, R., Blooms Schatten. Berlin: Matthes \& Seitz 2014.

Hänny, R., Flug. Frankfurt am Main: Suhrkamp 1985.

Hänny, R., Flug. Neue Fassung. Mit einem Nachwort von Samuel Moser. Frankfurt am Main: Suhrkamp 2007.

Hänny, R., HELLDUNKEL. Ein Bilderbuch. Frankfurt am Main: Suhrkamp 1994.

Hänny, R., Ruch. Ein Bericht. Frankfurt am Main: Suhrkamp 1979.

Hänny, R., Zum Aufbau von HELLDUNKEL, Manuskript, 2008.

Haupt, S., «Wie reimt sich Hermetik auf Helvetik? Streifzug durch die ,experimentelle` Literatur der Schweiz», neue deutsche Literatur 46 (1998) 521, 107-119.

Krättli, A., «,Ein Mann aus Wörtern‘. Essays, Interpretationen und Reportagen von Hermann Burger», Schweizer Monatshefte 64 (1984) 6, 540-543.

Krättli, A., «E. Y. Meyer», in: Arnold, H. L. (Hg.), Kritisches Lexikon zur deutschsprachigen Gegenwartsliteratur. München: edition + kritik 1994.

Laederach, J., Der zweite Sinn oder Unsentimentale Reise durch ein Feld Literatur. Frankfurt am Main: edition suhrkamp 1988.

Laederach, J., «Tranchierers Schweizwunder. Ein schwarzes Betbuch für den Winter oder das Ende der Moral: Der Roman ,Helldunkel` von Reto Hänny», Die Zeit Nr. 45, 4.11.1994.

Linsmayer, Ch., «Sprache als Kunst und Irritation», Der Bund, 27.10.1994.

Meier, G., Werke. Bd. 3: Baur und Bindschädler. Roman. Bern: Zytglogge 1987.

Mielczarek, Z., «Gedächtnis und Vorstellung: ,Der blaue Siphon“ von Urs Widmer», in: Mielczarek, Z. (Hg.), Nach den Zürcher Unruhen. Deutschsprachige Schweizer Literatur seit Anfang der achtziger Jahre. Konferenzbeiträge. Katowice: Wydawnictwo Uniwersytetu Śląskiego 1996, 20-31. 
Morlang. W., «Der Weltbürger aus Amrain», Neue Zürcher Zeitung Nr. 144, 23.06.2008, 23.

Moser, S., «der Fuchs ein Wolf der Text», in: Hänny, R., Flug. Neue Fassung. Mit einem Nachwort von Samuel Moser. Frankfurt am Main: Suhrkamp 2007, 243-258.

Moser, S., «Reto Hänny», in: Arnold, H. L. (Hg.), Kritisches Lexikon zur deutschsprachigen Gegenwartsliteratur. München: edition + kritik 1991.

Rüedi, P., «Fegefeuer. ,Helldunkel‘ von Reto Hänny: Bildlektüre», Weltwoche, 6.10.1994, 87.

Schmitz-Emans, M., «Wort-Zaubereien bei Hermann Burger», in: Baumberger, Ch. / Kolberg, S. / Renken, A., Literarische Polyphonien in der Schweiz. Bern, Berlin, Bruxelles [u. a.]: Peter Lang 2004 (Sammlung Variations), 41-70.

Sośnicka, D., Den Rhythmus der Zeit einfangen: Erzählexperimente in der Deutschschweizer Gegenwartsliteratur unter besonderer Berücksichtigung der Werke von Otto F. Walter, Gerold Späth und Zsuzsanna Gahse. Würzburg: Königshausen \& Neumann 2008.

Sośnicka, D., «,Polski orzeł na tle szwajcarskiego krzyża‘: Refleksje na temat recepcji współczesnej niemieckojęzycznej literatury szwajcarskiej w Polsce w nawiązaniu do utworu Reto Hänny'ego ,Am Boden des Kopfes. Verwirrungen eines Mitteleuropäers in Mitteleuropa '», in: Prace Naukowe Akademii im. Jana Dtugosza w Częstochowie. Studia Neofilologiczne XI (2015), 193-212. Doi: http://dx.doi.org/10.16926/sn.2015.11.12 [16.04.2018].

Sośnicka, D., Wie handgewobene Teppiche: Die Prosawerke Gerhard Meiers. Bern, Berlin, Bruxelles [u. a.]: Peter Lang 1999.

Weber, M. R., «Jürg Laederach», in: Arnold, H. L. (Hg.), Kritisches Lexikon zur deutschsprachigen Gegenwartsliteratur. München: edition + kritik 1995.

Wysling, H., Streifzüge. Literatur aus der deutschen Schweiz 1945-1991. Hrsg. u. eingeleitet v. H.-R. Schärer u. J.-P. Bünter. Zürich: Schulthess Verlag 1996.

Zeller, R., Der Neue Roman in der Schweiz: die Unerzählbarkeit der modernen Welt. Freiburg / Schweiz: Academic Press Fribourg 1992.

Zumsteg, S., ,poeta contra doctus'. Die perverse Poetologie des Schriftstellers Hermann Burger. Wien, New York: Springer 2011 (Edition Voldemeer). 